University of Nebraska - Lincoln

DigitalCommons@University of Nebraska - Lincoln

Papers in the Earth and Atmospheric Sciences

Earth and Atmospheric Sciences, Department

9-2019

\title{
Measurement and characterization of infrasound from a tornado producing storm
}

Brian R. Elbing

Christopher E. Petrin

Matthew Van Den Broeke

Follow this and additional works at: https://digitalcommons.unl.edu/geosciencefacpub

Part of the Atmospheric Sciences Commons, Earth Sciences Commons, and the Meteorology Commons

This Article is brought to you for free and open access by the Earth and Atmospheric Sciences, Department of at DigitalCommons@University of Nebraska - Lincoln. It has been accepted for inclusion in Papers in the Earth and Atmospheric Sciences by an authorized administrator of DigitalCommons@University of Nebraska - Lincoln. 


\title{
Measurement and characterization of infrasound from a tornado producing storm ${ }^{\text {a) }}$
}

\author{
Brian R. Elbing, ${ }^{1, b)}$ Christopher E. Petrin, ${ }^{1}$ and Matthew S. Van Den Broeke ${ }^{2}$ \\ ${ }^{1}$ Mechanical \& Aerospace Engineering, Oklahoma State University, Stillwater, Oklahoma 74078, USA \\ ${ }^{2}$ Earth and Atmospheric Sciences, University of Nebraska-Lincoln, Lincoln, Nebraska 68588, USA
}

(Received 5 June 2019; revised 9 August 2019; accepted 13 August 2019; published online 3 September 2019)

\begin{abstract}
A hail-producing supercell on 11 May 2017 produced a small tornado near Perkins, Oklahoma $(35.97,-97.04)$ at 2013 UTC. Two infrasound microphones with a 59-m separation and a regional Doppler radar station were located 18.7 and $70 \mathrm{~km}$ from the tornado, respectively. Elevated infrasound levels were observed starting $7 \mathrm{~min}$ before the verified tornado. Infrasound data below $\sim 5 \mathrm{~Hz}$ was contaminated with wind noise, but in the $5-50 \mathrm{~Hz}$ band the infrasound was independent of wind speed with a bearing angle that was consistent with the movement of the storm core that produced the tornado. During the tornado, a $75 \mathrm{~dB}$ peak formed at $\sim 8.3 \mathrm{~Hz}$, which was $18 \mathrm{~dB}$ above pre-tornado levels. This fundamental frequency had overtones $(18,29,36$, and $44 \mathrm{~Hz})$ that were linearly related to mode number. Analysis of a larger period of time associated with two infrasound bursts (the tornado occurred during the first event) shows that the spectral peaks from the tornado were present from $4 \mathrm{~min}$ before to $40 \mathrm{~min}$ after tornadogenesis. This suggests that the same geophysical process(es) was active during this entire window. (C) 2019 Acoustical Society of America. https://doi.org/10.1121/1.5124486
\end{abstract}

$[\mathrm{DKW}]$

Pages: $1528-1540$

\section{INTRODUCTION}

Numerous natural and anthropogenic sources emit infrasound, sound at frequencies below human hearing $(<20 \mathrm{~Hz})$. Known sources include severe storms (Jones and Georges, 1976; Talmadge and Waxler, 2016), earthquakes (Young and Greene, 1982; Le Pichon et al., 2005; Mutschlecner and Whitaker, 2005), explosions/rocket launches (Waxler et al., 2015; Blom et al., 2016), ocean waves (Waxler and Gilbert, 2006), and volcanoes (Johnson and Ripepe, 2011). Due to weak atmospheric absorption at low frequency and an "acoustic ceiling" within the atmosphere (Bedard and Georges, 2000), infrasound can be detected over significantly larger distances than audible sound. The infrasound carries information about the source, its location/movement, and the environment it passes through between the source and receiver. While this makes infrasound an appealing source for long-range, passive detection and monitoring of infrasound producing events (including tornadoes) as well as the environment it passes through, it makes identification and isolation of a specific source difficult. This is particularly true for tornadoes since they are rare, singular events, and their locations are unknown until minutes before formation. The current work reports field results from infrasound measurements located $\sim 19 \mathrm{~km}$ from a verified tornado. A strong infrasound signal was received during the tornado, and the focus of this paper is assessing the likelihood that the received signal was associated with the tornado.

A renewed focus on understanding tornado infrasound has been motivated by efforts to improve tornado warnings.

\footnotetext{
${ }^{\text {a) }}$ Part of this work was presented at the 175th meeting of the Acoustical Society of America in Minneapolis, MN, USA, May 2018.

b)Electronic mail: elbing@okstate.edu
}

This is especially important for the southeastern United States, where complex terrain, irregular road patterns, and nighttime tornadoes have contributed to a disproportionately large number of killer tornadoes. The Verification of the Origins of Rotation in Tornadoes Experiment - Southeast (VORTEXSE) aims to better understand the environmental factors associated with these tornadoes (Dumas et al., 2017; Lyza and Knupp, 2018; Lee et al., 2019; Wagner et al., 2019), and the National Oceanic and Atmospheric Administration (NOAA) has also funded complementary work focused on tornado infrasound in the Southeast. Georges (1973) notes that "the history of the discovery of severe-weather infrasound is clouded by an almost complete absence of early published results." Besides a few publications (Goerke and Woodward, 1966; Bowman and Bedard, 1971), documentation was primarily from internal reports or records of oral conference presentations. Unfortunately, this trend has not changed since these early findings. There were a few related publications in the 1970s (McDonald, 1974; Georges and Greene, 1975; Arnold et al., 1976) before the early 2000s when more activity focused on tornado infrasound. Contemporary work includes several oral presentations (Rinehart, 2012; Goudeau et al., 2018; Elbing et al., 2018a), conference papers (Noble and Tenney, 2003; Prassner and Noble, 2004; Bedard et al., 2004b; Bedard et al., 2004a), and a recent project report (Rinehart, 2018); but only a few journal articles (Bedard, 2005; Frazier et al., 2014; Dunn et al., 2016).

Bedard (2005) used an infrasonic observatory and collocated radar to track a velocity couplet aloft that evolved into a tornado and showed maximum circulation descending for $\sim 30 \mathrm{~min}$. The detected infrasound at $\sim 1 \mathrm{~Hz}$ followed the trend of the radar observations. In addition, Bedard (2005) notes that a reexamination of an archive of atmospheric infrasound recordings resulted in the identification of over 
100 cases with infrasonic signals produced at the time and in the direction of vortices, though few details of these 100 cases have been published. Frazier et al. (2014) examined high-fidelity acoustic recordings covering the frequency range from 0.2 to $500 \mathrm{~Hz}$ from three tornadoes in Oklahoma. Primary findings from this work are the use of beamforming at infrasound frequencies to track long-duration tornadoes, detection of audible frequency sound, and demonstration of a modified aeroacoustic jet turbulence model to predict the observed signature in the audible frequency range. Subsequently, this work is discussed further, particularly in reference to potential infrasound production mechanisms. Dunn et al. (2016) used a ring laser interferometer to detect infrasound from an EF4 tornado in Central Arkansas on 27 April 2014. Associated infrasound was observed $30 \mathrm{~min}$ before the tornado was initially reported and had a fundamental frequency of $0.94 \mathrm{~Hz}$. This is consistent with the observation of Bedard (2005) that large tornadoes produce infrasound in the $0.2-1 \mathrm{~Hz}$ range. Three additional vortices that ultimately produced tornadoes were claimed to have been detected at least $30 \mathrm{~min}$ before reported touchdown. Thus, there is strong evidence that infrasound is produced by a tornado (including during formation), but relatively few observations are well documented in the literature.

Given the dearth of detailed observations of tornado infrasound in the archival literature, the aim of the current work is not to attribute the infrasound observations to a specific tornado mechanism. A coherent understanding of the general mechanism(s) associated with infrasound production from tornadoes will require a broader sampling of infrasound from tornadoes. Consequently, the current objective is to establish confidence that the received signal was associated with the reported tornado and provide sufficient characterization of the storm and received infrasound such that it can be used to test proposed mechanisms. This includes a discussion of proposed mechanisms and whether they are consistent with available observations. The remainder of the paper includes characterization of the storm and tornado in Sec. II, analysis of infrasound during the tornado in Sec. III, discussion and analysis in Sec. IV, and conclusions in Sec. V.

\section{STORM AND TORNADO CHARACTERIZATION}

\section{A. Overview}

On 11 May 2017, a line of storms to the west of the infrasonic array included a hail-producing supercell. At 2013 UTC, the supercell produced a tornado, of unknown strength on the Enhanced Fujita scale (EFU), near Perkins, OK (35.97, -97.04), which was located $18.7 \mathrm{~km}$ south-by-east (SbE) of infrasound microphones at Oklahoma State University (OSU). The official tornado path length and damage width were $0.16 \mathrm{~km}(0.10$ miles $)$ and $46 \mathrm{~m}(150 \mathrm{ft})$ (NOAA, 2017), respectively. There were live news reports of a possible second tornado after the first, but it was never confirmed due to the storm being rain wrapped with no low-level radar coverage. Confirmed hail events during the life of the supercell that produced the tornado are provided in Table I, which includes the hail size, UTC time, time relative to the reported tornado touchdown $\left(t_{r}\right)$, latitude (lat), longitude
TABLE I. Confirmed hail and tornado events within $100 \mathrm{~km}$ of the infrasound array during the life of the storm that produced the tornado on 11 May 2017. For hail, the size is the reported diameter in millimeters.

\begin{tabular}{lccccccc}
\hline \hline Event & Size & Time $(\mathrm{UTC})$ & $t_{r}(\mathrm{~min})$ & Lat & Lon & $L(\mathrm{~km})$ & $\varphi\left(^{\circ}\right)$ \\
\hline Hail & 25 & $19: 25$ & -48 & 35.95 & -97.59 & 50.2 & 65.7 \\
Hail & 38 & $19: 38$ & -35 & 35.84 & -97.41 & 44.2 & 42.0 \\
Hail & 38 & $19: 40$ & -33 & 35.88 & -97.39 & 39.7 & 44.4 \\
Hail & 51 & $19: 45$ & -28 & 35.95 & -97.28 & 27.2 & 41.0 \\
Hail & 44 & $19: 50$ & -23 & 35.95 & -97.25 & 25.5 & 36.4 \\
Hail & 70 & $19: 51$ & -22 & 35.95 & -97.26 & 26.1 & 38.0 \\
Hail & 70 & $19: 53$ & -20 & 35.95 & -97.25 & 25.5 & 36.4 \\
Hail & 44 & $19: 56$ & -17 & 35.95 & -97.26 & 26.1 & 38.0 \\
Hail & 108 & $19: 56$ & -17 & 35.95 & -97.24 & 25.0 & 34.7 \\
Hail & 64 & $20: 06$ & -7 & 35.84 & -97.25 & 36.1 & 24.8 \\
Tornado & EFU & $20: 13$ & 0 & 35.97 & -97.04 & 18.7 & -11.5 \\
Hail & 22 & $21: 13$ & 60 & 36.22 & -96.57 & 46.7 & -101.8 \\
Hail & 19 & $21: 15$ & 62 & 36.12 & -96.58 & 45.1 & -88.3 \\
\hline \hline
\end{tabular}

(lon), distance between event and the array $(L)$, and the bearing angle $(\varphi)$ measured from the source to the receiver clockwise relative to north $\left(0^{\circ}\right)$. The largest confirmed hail was $108 \mathrm{~mm}$ (4.25 in) that was reported $25 \mathrm{~km}$ to the southwest of the infrasonic array at 1956 UTC. There were two reports of hail approximately an hour after the tornado with both events being east of the infrasound microphones.

\section{B. Ground-level atmospheric conditions}

Ground-level atmospheric conditions were monitored by Oklahoma Mesonet stations (Brock et al., 1995; McPherson et al., 2007) and a weather station (termed DML) located $\sim 170 \mathrm{~m}$ south of the infrasonic array. The DML weather station (Vantage Pro, Davis Instruments) was located on a building roof and provided $30 \mathrm{~min}$ averages of temperature, humidity, atmospheric pressure, and wind speed. The Oklahoma Mesonet network consists of 120 automated environmental monitoring stations that measure air temperature $1.5 \mathrm{~m}$ above ground, relative humidity $1.5 \mathrm{~m}$ above ground, wind speed and direction $10 \mathrm{~m}$ above ground, barometric pressure, rainfall, incoming solar radiation, and soil temperature. Data are packaged in $5 \mathrm{~min}$ "observations" that are quality checked by the Oklahoma Climatological Survey prior to being released. The current study used three sites: Perkins (PERK), Stillwater (STIL), and Marena (MARE).

The Perkins (PERK), Stillwater (STIL), and Marena (MARE) Mesonet stations were located $3.3 \mathrm{~km}$ north-bywest $(\mathrm{NbW})$ of the tornado (15.4 $\mathrm{km}$ to array), $17.5 \mathrm{~km} \mathrm{NbW}$ of the tornado $(1.9 \mathrm{~km}$ to array), and $18.8 \mathrm{~km}$ northwest-bywest of the tornado $(14.1 \mathrm{~km}$ to array), respectively. These stations, in addition to the DML weather station, were used to characterize the ground-level atmospheric conditions and corresponding speed of sound. The measured air temperature, computed speed of sound in humid air (Cramer, 1993), wind speed, and wind direction from each site for the two hours before and after the tornado are provided in Fig. 1 with the time $\left(t_{r}\right)$ shown relative to the tornado report (11 May 2017, 2013 UTC). The general trends between the sites are all comparable with the primary differences of note being 

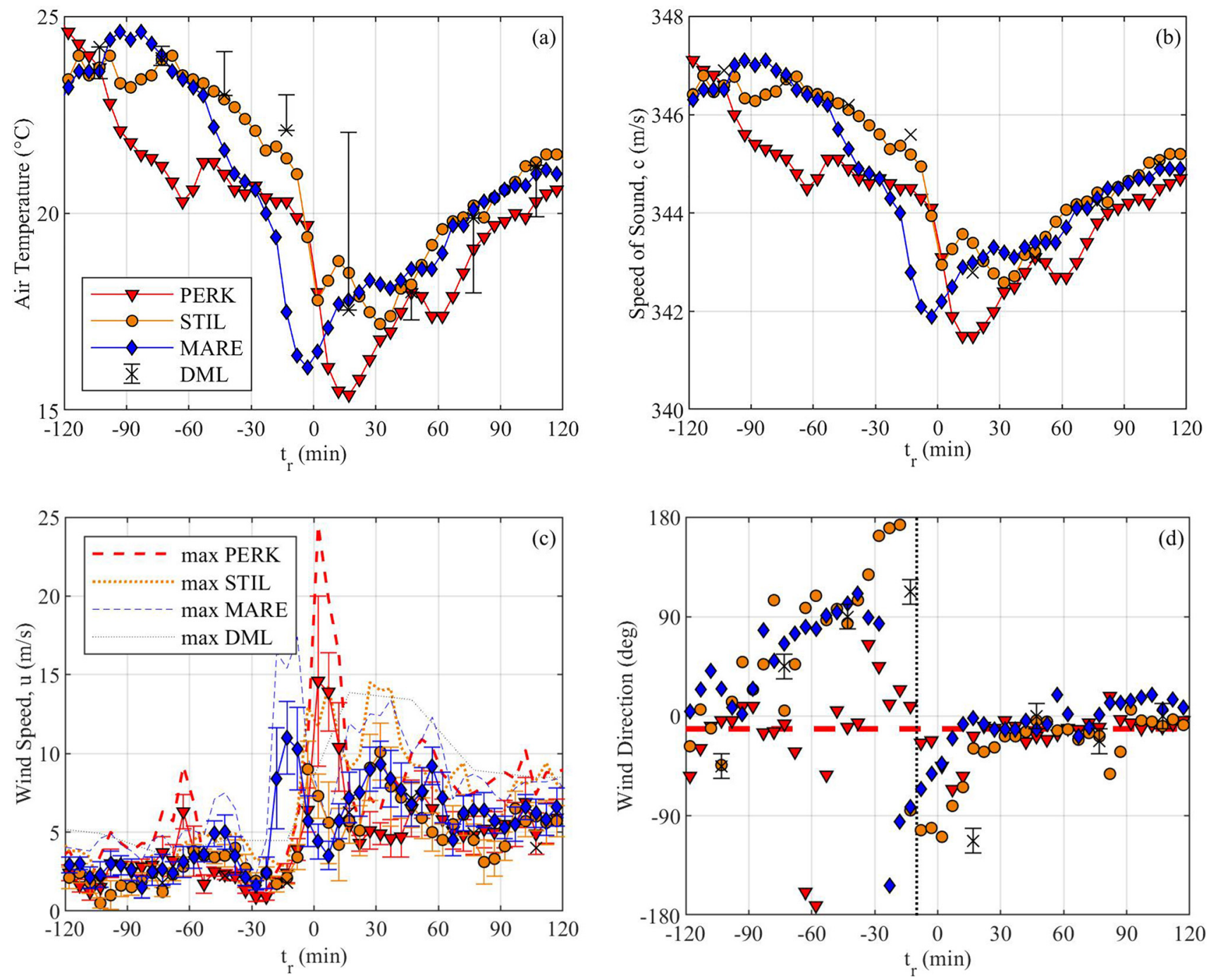

FIG. 1. (Color online) Ground level atmospheric state from the Mesonet and DML weather stations including: (a) Average air temperature with DML error bars being the maximum deviations from the average, (b) speed of sound in humid air, (c) wind speed including maximum 3-s observations, and (d) the wind direction.

that the minimum temperature occurred earlier at MARE and higher wind speeds were observed at PERK. The higher wind speed was due to the close proximity of the PERK site to the tornado producing storm, and the earlier temperature drop at MARE was due to it being farther west (i.e., the storm reached this site earlier). Of particular note is that the wind direction at PERK from $\sim 10$ min before the tornado [marked with a vertical dashed line in Fig. 1(d)] through the life of this storm was aligned with the direction from the tornado to the infrasound array [horizontal dashed line in Fig. 1(d)].

\section{Radar analysis}

Data were analyzed from the Weather Surveillance Radar1988 Doppler (WSR-88D) at Oklahoma City, Oklahoma (KTLX; 35.33306, -97.27778), which is located $\sim 70 \mathrm{~km}$ southwest of the verified tornado (Fig. 2). At this range, the base-scan radar beam height was $\sim 0.95 \mathrm{~km}$ above radar level (ARL). Data were analyzed from 1928 UTC on 11 May 2017 ( $\sim 5 \mathrm{~min}$ prior to tornadogenesis) to $2103 \mathrm{UTC}$, when the storm became too far from the radar for good data quality.

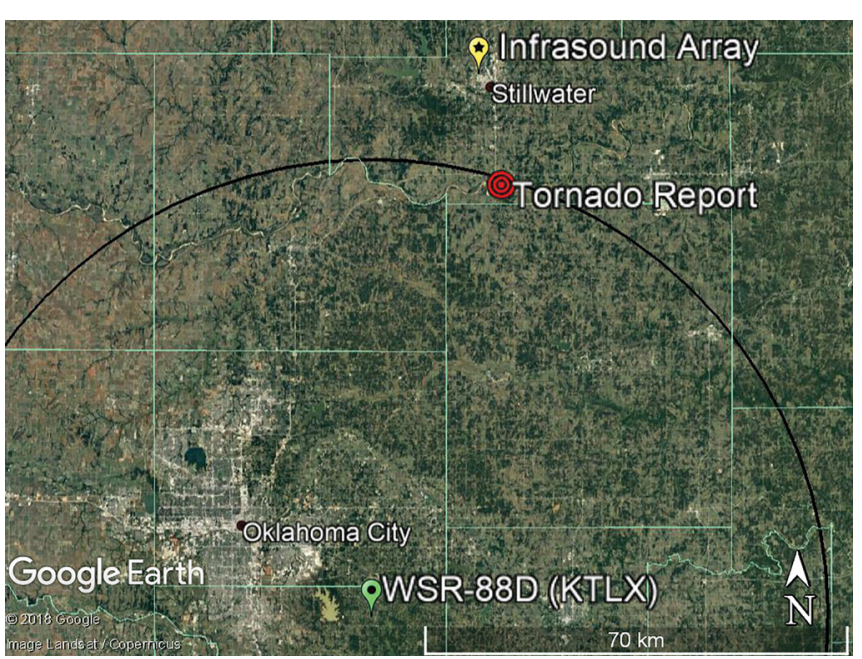

FIG. 2. (Color online) Map showing the location of the WSR-88D radar at Oklahoma City (KTLX). Black circle (radius $75 \mathrm{~km}$ ) indicates the region where the base-scan beam altitude was less than $1 \mathrm{~km} \mathrm{ARL}$, assuming standard beam propagation. 

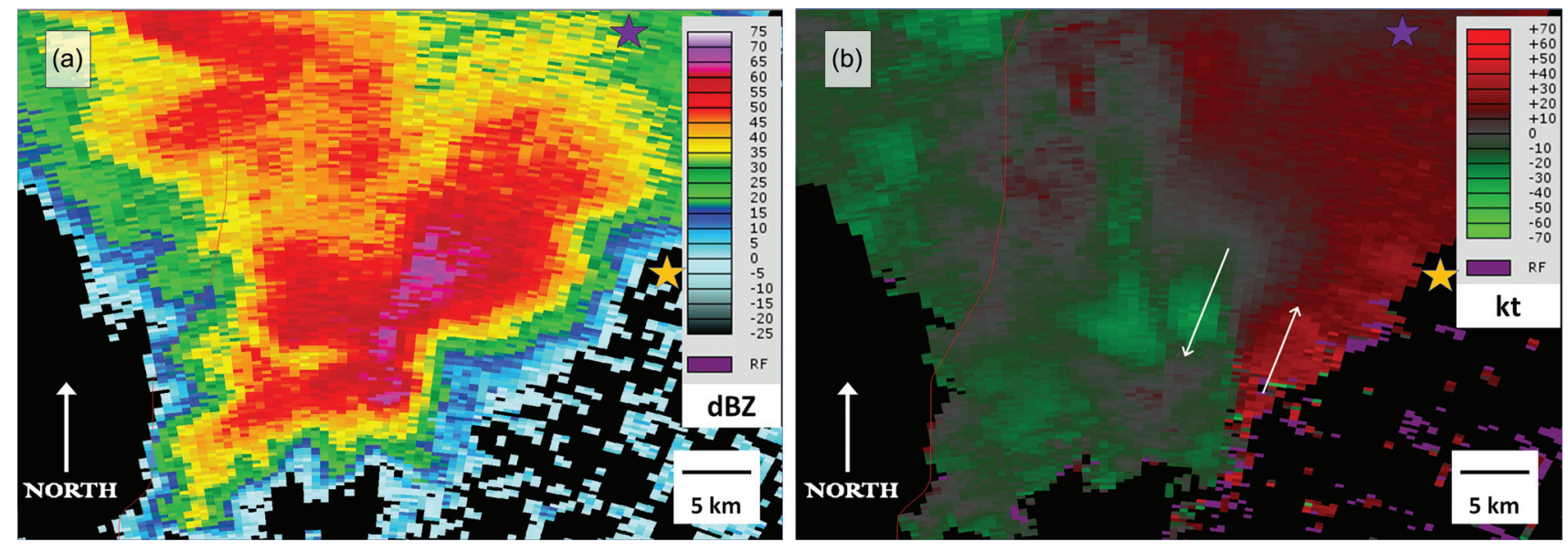

FIG. 3. (a) Radar reflectivity factor and (b) radial velocity from KTLX at 1953 UTC on 11 May 2017. Data are base-scan, with an altitude of $\sim 0.88$ km ARL near the storm core. Arrows in (b) indicate the inbound and outbound velocities associated with the low-level mesocyclone. In each panel, gold and purple stars indicate the eventual tornado and infrasound array locations, respectively.

Around this time, other nearby storms began to merge with the storm of interest.

Several radar metrics were analyzed through the analysis period for the storm of interest (11 May 2017 from 1928 to 2045 UTC). Base-scan data (radar reflectivity factor and radial velocity) at an altitude of $\sim 0.88 \mathrm{~km}$ ARL near the storm core at 1953 UTC are shown in Fig. 3. The velocity difference near the surface and associated with the tornadic vortex cannot be robustly analyzed for this event because of its distance from the radar site. Compounding this problem is the small size of the tornado (estimated width $\sim 50 \mathrm{~m}$ at the ground), meaning that radar observations at this distance are incapable of measuring maximum wind speeds toward and away from the radar within the tornado. Instead, maximum radial velocity difference (MRVD) was derived for the low-level mesocyclone at base scan, at an altitude of $\sim 1 \mathrm{~km}$ ARL. This storm had a well-defined mesocyclone [Fig. 3(b)], so maximum velocity difference was computed as the difference between the associated maximum inbound and outbound velocities. This analysis was done from 1928 to 2045 UTC, since beyond this time the storm-radar distance increased to too large of a value for velocity difference values to remain comparable.

Through the analysis period, the MRVD in the lowlevel mesocyclone ranged from 13.5 to $42.5 \mathrm{~m} / \mathrm{s}$ (Fig. 4). The mesocyclone was relatively weak for a few time steps after initiating but was well-defined and reasonably strong by 1940 UTC (Fig. 4, MRVD). The low-level mesocyclone reached its maximum intensity at 2000 UTC, $\sim 13$ min prior to reported tornadogenesis. Shortly after tornadogenesis, the intensity of the low-level mesocyclone decreased sharply and did not recover during the analysis period. Radar beamcenterline altitude did not change substantially with the lowlevel mesocyclone intensity, indicating that the observed MRVD changes were genuine changes to storm organization and not an effect of radar beam propagation.

The base-scan normalized hail areal extent (NHAE) $>35 \mathrm{dBZ}$ in radar reflectivity factor $\left(Z_{H H}\right)$ (Van Den Broeke, 2017) was also analyzed. NHAE uses a combination of $Z_{H H}$ and differential reflectivity $\left(Z_{D R}\right.$; e.g., Doviak and Zrnić,
2006) to identify areas where hail is present. NHAE is normalized by the storm area, which makes it a percentage of the base-scan storm area $>35 \mathrm{dBZ}$ dominated by hail and allows for comparison between storms. The time history of the NHAE is also shown in Fig. 4. An initial burst of hail around 1947 UTC ( $t_{r} \approx-26 \mathrm{~min}$ ) is followed by a secondary burst of hailfall from 2006 to 2013 UTC ( $-7 \mathrm{~min}$ $\left.<t_{r}<0 \mathrm{~min}\right)$. Prior work has noted that hailfall is often maximized in the minutes leading up to tornadogenesis (Browning, 1965; Van Den Broeke et al., 2008). Of note, the majority of the reported hail for this storm occurred in the time spanning these two hailfall bursts with the largest reported hail occurring at $t_{r}=-17 \mathrm{~min}$ (Table I). Area of the storm dominated by hail decreased markedly after tornado demise (Fig. 4).

\section{INFRASOUND DURING THE TORNADO}

\section{A. Infrasound data acquisition}

A 3-microphone (model 24, Chaparral Physics) infrasonic array was deployed on the campus of OSU during the 2017 tornado season. This effort was part of the CLOUDMAP project (Elbing and Gaeta, 2016; Hemingway et al.,

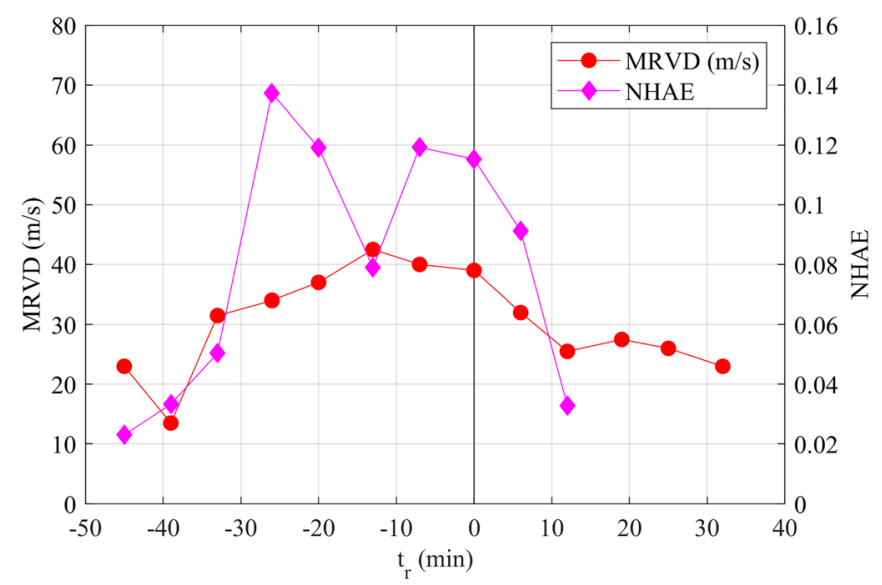

FIG. 4. (Color online) Time series of MRVD and of the NHAE from 1928 to 2025 UTC. 


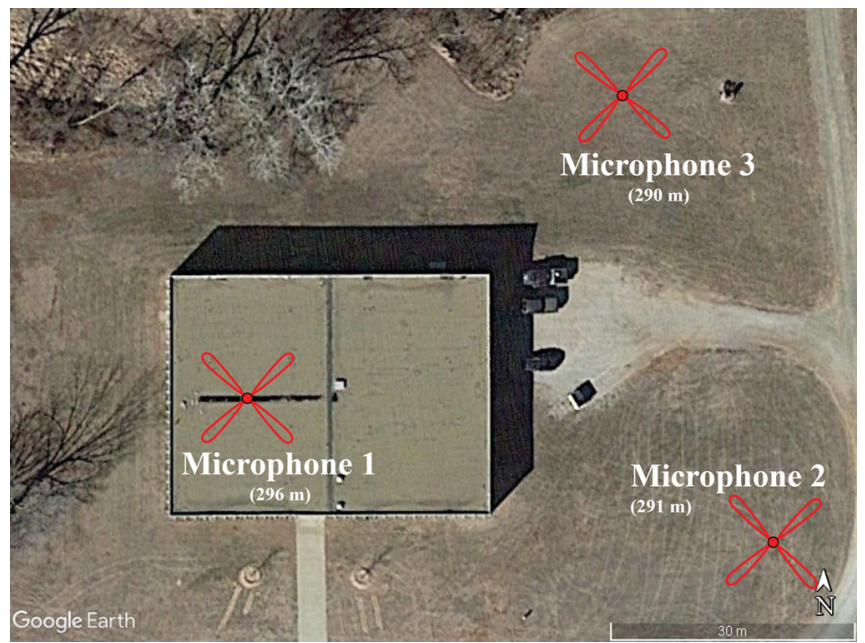

FIG. 5. (Color online) Satellite image of the OSU infrasonic array. Microphone locations are labelled and denoted by the " $\mathrm{X}$ " and microphone elevation listed.

2017; Smith et al., 2017; Jacob et al., 2018), a multiuniversity collaboration focused on the development and implementation of unmanned aerial systems (UAS) and their integration with sensors for atmospheric measurement. The infrasonic array, satellite image shown in Fig. 5, was centered at $(36.1344,-97.0815)$ and the coordinates for each microphone as well as the separation distances are provided in Table II. Tornadoes generally produce infrasound between $0.5 \mathrm{~Hz}(\lambda \approx 686 \mathrm{~m})$ and $10 \mathrm{~Hz}(\lambda \approx 34.3 \mathrm{~m})$, where $\lambda$ is the acoustic wavelength. Bedard (1998) recommended a nominal spacing of $\lambda / 4$ between microphones in an array, though $\lambda / 2$ is more widely accepted. Using the half- $\lambda$ spacing, the ideal spacing between microphones is $343 \mathrm{~m}$. Space limitations resulted in the final spacing of $\sim 60 \mathrm{~m}$, which makes it tuned to $\sim 3 \mathrm{~Hz}$ (half- $\lambda$ spacing). Each microphone had a nominal sensitivity of $\sim 400 \mathrm{mV} / \mathrm{Pa}$ and a nearly flat response from 0.1 to $200 \mathrm{~Hz}$. All the microphones had identical mounting structure that included a low-frequency vibration isolation pad with the microphone sealed within an acrylic dome painted white. The mounting followed guidelines from the manufacture to mitigate the impact of rapid temperature variations. Windscreens were produced using four 15-m long porous hoses connected to each microphone for spatially averaging to cancel out incoherent noise (e.g., wind). The microphones with and without the windscreens (hoses) were tested in an anechoic chamber (though not anechoic to infrasound frequencies) in a method similar to that of Hart and McDonald (2009). These results showed

TABLE II. Summary of locations for each of the microphones, mounting location (roof or ground level), and the separation distance between the microphones.

\begin{tabular}{|c|c|c|c|c|c|c|c|}
\hline & \multicolumn{4}{|c|}{ Location } & \multicolumn{3}{|c|}{$\begin{array}{c}\text { Separation } \\
\text { Distances }(\mathrm{m})\end{array}$} \\
\hline & Latitude & Longitude & $\begin{array}{l}\text { Elevation } \\
(\mathrm{m})\end{array}$ & Mounting & Mic 1 & Mic 2 & Mic 3 \\
\hline Mic 1 & 36.1344 & -97.0819 & 296 & Roof & 0 & 67.6 & 58.6 \\
\hline Mic 2 & 36.1342 & -97.0813 & 291 & Ground & 67.6 & 0 & 58.5 \\
\hline Mic 3 & 36.1347 & -97.0814 & 290 & Ground & 58.6 & 58.5 & 0 \\
\hline
\end{tabular}

significant reduction in wind noise below $50 \mathrm{~Hz}$ without significant attenuation of a reference signal, but no noise reduction by $100 \mathrm{~Hz}$ (Threatt, 2016). The microphones were powered with DC-power supplies (APS-1303, Aktakom). The output from each microphone was recorded via a dynamic signal analyzer (USB-4432, National Instruments). The data acquisition was controlled via a commercial software package (Sound \& Vibration Measurement Suite, National Instruments). The sample rate was fixed at $1 \mathrm{kHz}$ and grouped in 20-min observation windows. Unfortunately, there was cross-talk between microphones 2 and 3 that was not identified until after the reported observation. However, the current analysis includes microphone 3 data because cross-talk was only confirmed in microphone 2 and, even with the cross-talk, it contains independent data (though potentially contaminated with "noise" from microphone 2).

\section{B. Time series analysis}

The time trace of microphones 1 and 3 are provided in Fig. 6 with the time $\left(t_{r}\right)$ relative to the tornado report (11 May 2017, 2013 UTC). It is apparent that a signal that was significantly stronger than the background levels peaks close to the time of the tornado report, and a second strong event begins $\sim 20 \mathrm{~min}$ after the reported tornado touchdown. While seemingly aligned with the tornado report (and a potential, un-confirmed rain wrapped second tornado), inspection of the wind speed (STIL Mesonet) time trace (included in Fig. 6) shows that the elevated infrasound levels are correlated with when the wind speed exceeds $\sim 5 \mathrm{~m} / \mathrm{s}$. This is consistent with Pepyne and Klaiber (2012) that observed that porous hose filters were not effective windscreens when the wind exceeds $5 \mathrm{~m} / \mathrm{s}$. This is also consistent with the fact that microphone 3 (as well as microphone 2, not shown) was attenuated relative to microphone 1 since microphone 1 was elevated and microphones 2 and 3 are on the ground with some natural wind breaks (e.g., trees, buildings) surrounding them. In addition, there is a possibility that the porous hoses on microphones 2 and 3 were infiltrated by rain water due to

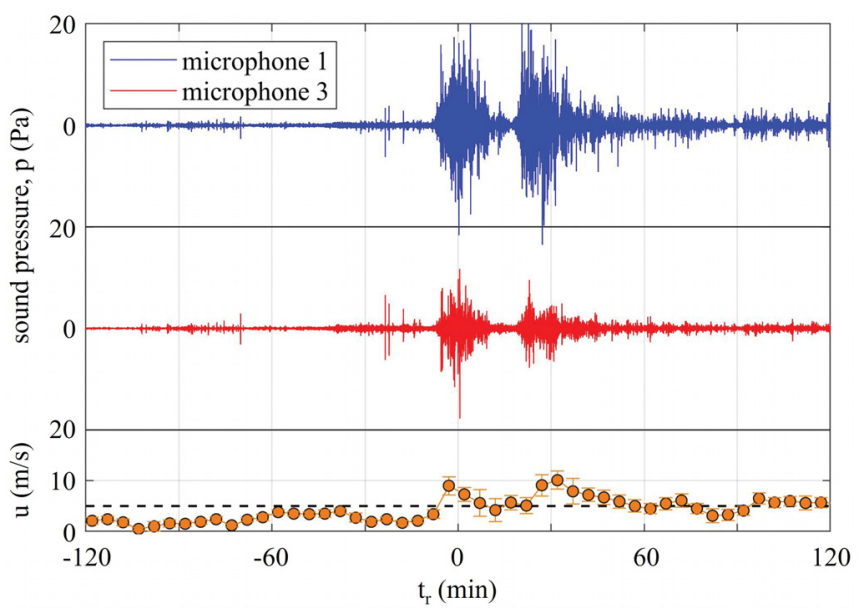

FIG. 6. (Color online) The measured sound pressure versus time in minutes relative to the tornado touchdown (11 May 2017, 2013 UTC) for microphones 1 and 3 with the amplitude of microphone 3 shifted for clarity. The time trace of the STIL Mesonet site with a reference dashed line at $5 \mathrm{~m} / \mathrm{s}$ is also included for comparison. 
being laid directly on the ground. Conversely, microphone 1 was on a roof with good drainage and the porous hoses were elevated $38 \mathrm{~mm}$ above the surface. For these and other issues (Hart and McDonald, 2009; Pepyne and Klaiber, 2012), there is active research searching for alternative windscreen options (e.g., close-cell dense foam; Zuckerwar, 2010; Shams et al., 2005; Shams et al., 2013; Alberts et al., 2013; Dauchez et al., 2016) with most infrasound researchers moving to the use of porous domes (Talmadge, 2018; Pitre and Petculescu, 2019).

These infrasound signals are nonstationary, but for the purpose of analysis such signals can often be viewed as piecewise stationary. This requires a means of identifying the appropriate period, which is challenging since this is a singular event (i.e., a unique tornado with additional, unknown background infrasound sources). Here the analysis method of Bendat and Piersol (2000) for a nonstationary single record is followed with the assumption that the single measurement is the product of a deterministic function and a random process. This analysis demonstrates that increasing the averaging period $T$ reduces the random errors but increases the bias error. Thus, the selection of the period is critical for an accurate representation of the data during the analysis. For the current work, the appropriate averaging period was determined from the trial-and-error approach (Bendat and Piersol, 2000). Figure 7 shows the squared effective pressure, $P_{e}^{2}=1 / T \int_{0}^{T} p^{2} d t$, from microphone 1 with averaging periods from 0.01 to $1000 \mathrm{~s}$ (additional periods were examined, though not shown). From these results it is clear that $T=0.01$ and $10 \mathrm{~s}$ still have abrupt variations from one sample to the next, which is indicative of random errors. Conversely, the results of $T=1000 \mathrm{~s}$ shows a significant bias error as illustrated from the observation that $P_{e}^{2}$ increases before the actual infrasound signal rises as $t_{r}=-7 \mathrm{~min}$ and $20 \mathrm{~min}$. Thus, from trial-and-error, a final averaging period of $T=100 \mathrm{~s}$ was determined. Consequently, subsequent data analysis was performed within $100 \mathrm{~s}$ windows.

\section{Spectral analysis}

The sound pressure spectra, $\Phi(f)$, presented herein are the single-sided form such that

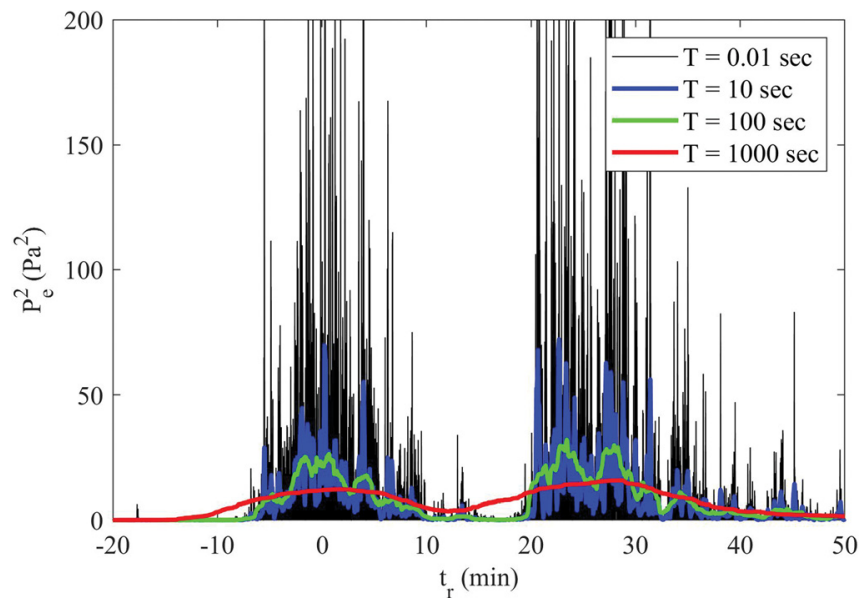

FIG. 7. (Color online) Squared effective pressure $\left(P_{e}{ }^{2}\right)$ versus time with a wide range of averaging periods. The longest period $(T=1000 \mathrm{~s})$ creates a large bias error as evident at $t_{r} \sim 17 \mathrm{~min}$.

$$
P_{r m s}^{2}=\int_{0}^{\infty} \Phi(f) d f
$$

where $P_{r m s}^{2}$ is the pressure variance and $f$ is the temporal frequency. For the current analysis, the period of time when the tornado was present was set at $-46<t_{r}<154 \mathrm{~s}$, which corresponds to $\pm 100 \mathrm{~s}$ from the nominal time arrival for the direct path acoustic wave $\left(t_{r}=54 \mathrm{~s}\right)$. The $\pm 100 \mathrm{~s}$ window was selected because it is consistent with the averaging period previously determined as well as being nominally consistent with the level of accuracy with which it is known the tornado was present. To determine the pressure spectra during the tornado, the period of interest $\left(-46<t_{r}<154 \mathrm{~s}\right)$ was segmented into $100 \mathrm{~s}$ periods with $75 \%$ overlap. The square of the double-sided fast Fourier transform (FFT) was multiplied by two to give the single-sided sound pressure spectra (i.e., power spectral density). The accuracy of each spectrum was checked against Eq. (1), and the variation was less than $1 \%$ for all computed spectra. All of the individual spectra within the window of interest were averaged to provide the mean spectrum. Results from microphone 1 (individual segments as well as the mean spectrum) during the tornado are provided in Fig. 8 with the sound pressure spectra reported in decibels referenced to $20 \mu \mathrm{Pa}$. Here there is gradual decay in the power spectral density from $\sim 0.1 \mathrm{~Hz}$ until a broad peak is observed between 5 and $14 \mathrm{~Hz}$. The elevated spectral levels below $5 \mathrm{~Hz}$ are likely due to wind noise, which is supported by the infrasound amplitude at these low frequencies being well correlated with the local wind speed (see Elbing et al., 2018b). The broad peak was smoothed with a $1 / 50$ th decade filter and then the maximum energy was used to identify the peak of $75 \mathrm{~dB}$ at $8.3 \mathrm{~Hz}$ with a quality factor of 1.6. The quality factor $\left(Q=f_{p k} /\left(f_{U}-f_{L}\right)\right)$ is a measure of the bandwidth of the peak, where $f_{U}$ and $f_{L}$ are the frequency $3 \mathrm{~dB}$ below the peak on the upper and lower side of the peak, respectively. Following the initial peak at $\sim 8.3 \mathrm{~Hz}$, there are overtones with nominal peaks at 18, 29, 36 , and $44 \mathrm{~Hz}$, which have quality factors $(Q)$ of $3.4,3.8$,

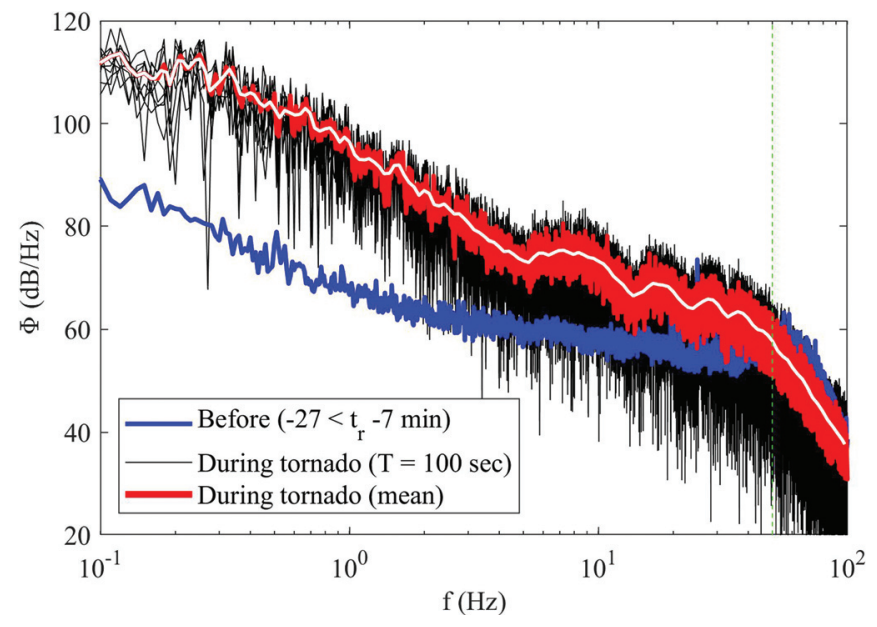

FIG. 8. Sound pressure spectra during the nominal time of arrival of signals emitted from the verified tornado $\left(-46<t_{r}<154 \mathrm{~s}\right)$ compared with the sound pressure spectra before the rise in infrasound (blue line). Thin black lines correspond to spectra from individual $100 \mathrm{~s}$ intervals, and the thin white line is the mean with a $1 / 50$ th decade filter applied. 
4.8 , and 4.9 , respectively. After the last overtone, there is a rapid roll-off associated with the low-pass filter created by the porous hose windscreens. The fundamental frequency $(8.3 \mathrm{~Hz})$ peak was $\sim 18 \mathrm{~dB}$ above the levels before the rise in infrasound associated with the tornado $\left(-27<t_{r}<-7 \mathrm{~min}\right)$.

\section{Bearing angle estimate}

As the larger amplitude content was likely associated with wind noise, the question is whether these other peaks are associated with the tornado. The cross-talk contamination between microphones 2 and 3 prevents bearing angle calculation without applying assumptions about the resulting pressure wave and its orientation. However, it is possible to answer the question of whether the received signals are consistent with what is expected if they were produced by the tornado. For this analysis, it is assumed that the distance between the tornado and the array $(18.7 \mathrm{~km})$ was sufficient that the received signals are well approximated as plane waves. Given the speed of sound $(343.8 \mathrm{~m} / \mathrm{s}$; mean from STIL, DML, PERK) and the frequency range of interest $(5<f<14 \mathrm{~Hz})$, the distance between the array and tornado corresponds to 270 to 760 wavelengths. Next, it is assumed that the received signals were propagating parallel to the ground directly from the source with negligible impact due to the elevation difference between microphones (difference in propagation between the surface and the elevated sensor introduces a bias error for broadband signals). Note that given a range of $18.7 \mathrm{~km}$ with possible cross-wind propagation, this assumption adds uncertainty to the calculations.

The bearing angle of the filtered signal was determined with time-domain beamforming using the time difference of arrival technique (Dowling and Sabra, 2015). The separation (or lag) time between microphones 1 and $3\left(t_{13}=t_{1}-t_{3}\right)$ was determined from the peak in the cross-correlation between the two signals. Given the assumptions, there are two valid bearing angles mirrored about the line between microphones 1 and 3 (if the horizontal plane wave assumption were not applied this would represent a cone). The speed of sound $(c)$ and the distance between microphones 1 and $3\left(L_{13}\right)$ can be used to define the angle between the plane wave front relative to the line connecting microphones 1 and $3, \theta=\cos ^{-1}\left(c\left|t_{13}\right| / L_{13}\right)$. Then with geometric relationships, the bearing angle of the received signal $(\varphi)$ and its mirrored result $\left(\varphi^{\prime}\right)$ can be determined with the angle measured positive clockwise from north $\left(0^{\circ}\right)$.

The sensitivity of the bearing angle to the processing parameters showed the largest measurement uncertainty. Thus, the bearing angle was computed by applying a 5th order Butterworth bandpass filter with the minimum and maximum cutoff frequencies incrementally varied between 5.5 and $11.5 \mathrm{~Hz}$ and 40 and $50 \mathrm{~Hz}$, respectively. These frequency ranges were selected because they nominally span the width of the fundamental peak and the 4 th overtone, respectively. In addition, the segment period and overlap percentage between segments was varied, which produced a total of 189 computed bearing angles per time step. In Fig. 9, the resulting time history of the mean bearing angle for the received infrasound signals is shown with the error bars

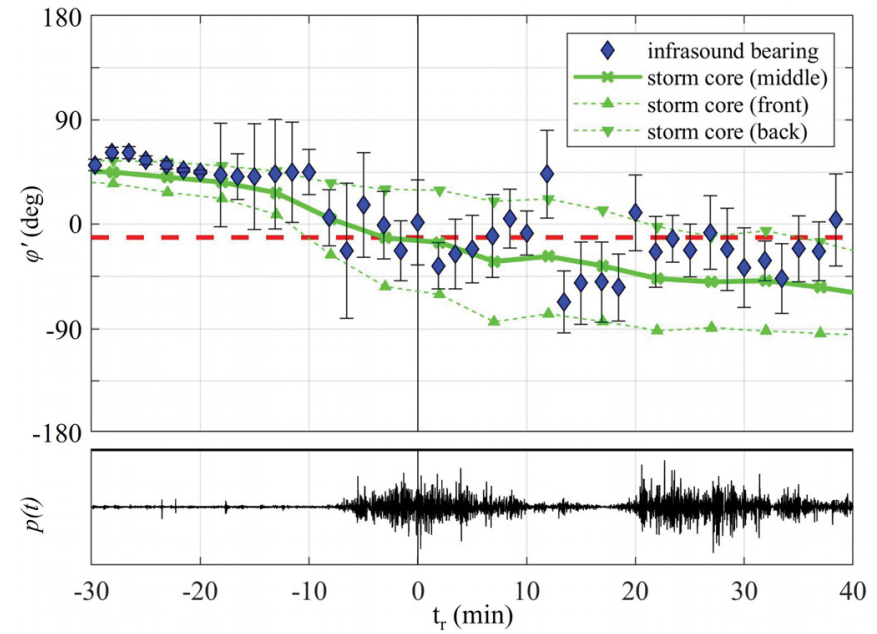

FIG. 9. (Color online) Bearing angle $\left(\varphi^{\prime}\right)$ of the received signal bandpass filtered between 5 and $50 \mathrm{~Hz}$. The horizontal dashed line is the tornado bearing angle. The other dashed lines correspond to the nominal bearing angles of the leading or trailing edges of the storm core while the solid line is the storm core center. Sound pressure time trace is also included for reference. Mirrored bearing angles are omitted for clarity.

equal to the standard deviation determined from variation of the processing parameters. Only $\varphi^{\prime}$ is shown in Fig. 9 for clarity since this analysis is simply to show that the directionality of the received signals are consistent with that expected from the tornado. For comparison, the relative bearing angles for the front, middle, and back side of the storm core that produced the tornado are also provided in Fig. 9. Here the "storm core" location was defined via radar reflectivity as the region of the storm that produced the tornado with $>50 \mathrm{dBZ}$ at a nominal elevation of $1 \mathrm{~km}$. In addition, a horizontal reference line at the bearing angle corresponding to the tornado report $\left(\varphi_{\text {tornado }}=-11.5^{\circ}\right)$ is included, which intersects the storm core center curve at $t_{r}=0$. It should be noted that at $\sim 2035$ UTC $\left(t_{r} \approx 22 \mathrm{~min}\right.$ ), the storm core breaks into two segments with the bearing angles shown corresponding to the front and back of the leading and trailing segments, respectively.

While there is significant scatter in the results, the mean bearing angles track with the general storm core direction with the majority of data points falling between the bearing angles corresponding to the leading and trailing edges of the storm core. Ultimately, given the applied assumptions and known noise contamination from the other microphone, the bearing angles are nominally consistent with what would be expected if emitted from the reported tornado location. This gives corroborative evidence that the infrasound signal of interest originated from the region within the storm that produced the tornado.

\section{DISCUSSION AND ANALYSIS}

\section{A. Characterization of events (infrasound bursts)}

The time trace of the sound pressure (Fig. 6) shows that there were two distinct infrasound bursts or events. This is interesting given the possibility of a second tornado that was not confirmed due to the rain wrapped storm and lack of low-level radar. Examination of the sound pressure and the 
cross-correlation from microphones 1 and $3, C_{1,3}(t)$ $=1 / T \int_{0}^{T} P_{1}(\tau) P_{3}(\tau+t) d \tau$, showed elevated sound pressure and correlation levels during $-7 \leq t_{r} \leq 52$ minutes, where $\tau$ is the lag (or shifted) time between signals. A more detailed examination inside of this window shows that the spectral peaks seen in Fig. 8 first appear at $t_{r}=-4$ minutes, and they persist until $t_{r}=+40$ minutes, including the period between the two bursts where the sound pressure levels were reduced. Figure 10 shows the pressure spectra during event $1\left(-4<t_{r}\right.$ $<11 \mathrm{~min})$, event $2\left(19<t_{r}<40 \mathrm{~min}\right)$, the period between events 1 and 2, and the spectra before and after the rise in infrasound.

First, it is important to note that the power spectra during the larger window of event 1 are nearly identical to those of the narrow window used to analyze Fig. 8. Furthermore, events 1 and 2 are also nearly identical, which suggests that they are both related to a similar physical process(es). It is also interesting that the relatively quiet period between the two events had pressure spectra that looked similar to events 1 and 2, though at reduced levels. This suggests that the same mechanism was active throughout the period of interest with the source either weakening for a period or the propagation path changing (e.g., wind speed/direction, source elevation, storm structure, etc.). Here we note that, while the infrasound community has made great advances in the study of acoustic propagation of infrasound (Ostashev et al., 2005; Le Pichon et al., 2010; Waxler and Assink, 2017; Shang et al., 2019; Sabatini et al., 2019), no corrections for propagation effects have been applied for the current work. For $t_{r}$ $>40 \mathrm{~min}$, the tones are lost even though the spectra levels in the $5-50 \mathrm{~Hz}$ band remain elevated, but they did drop to comparable levels as before event 1 for frequencies above $\sim 5 \mathrm{~Hz}$. Below $5 \mathrm{~Hz}$, the signal remains elevated above the background levels, which is associated with the wind noise and can be seen in Fig. 6 with higher wind speeds and sound pressure levels.

While the fundamental frequency and the associated overtones during the tornado were identified from the power spectra discussion, it is informative to precisely identify the

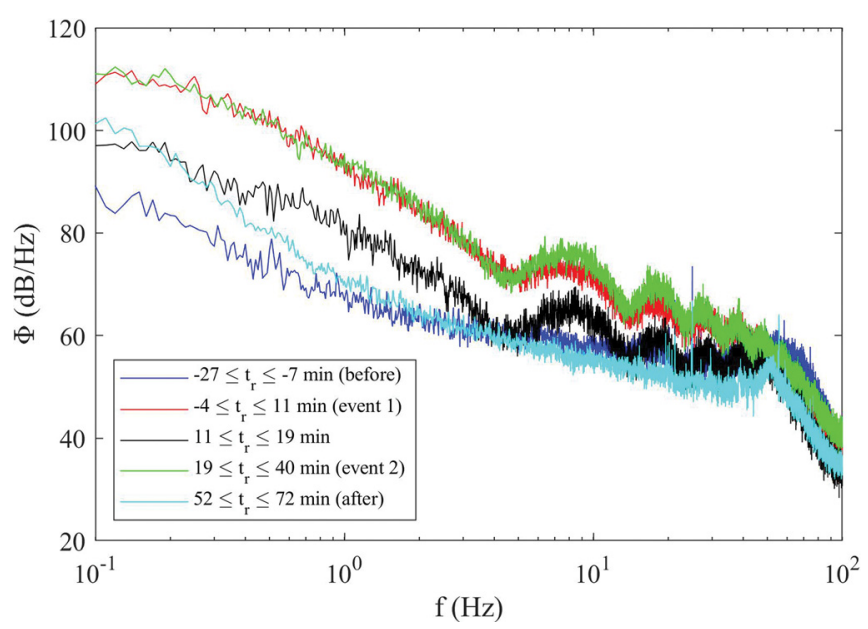

FIG. 10. (Color online) Comparison of the pressure power spectra during the infrasound bursts (events), the period between the events, and for reference the spectra before and after these events. peaks during the various periods of interest. The fundamental and first four overtones were identified for periods before, during, and after both infrasound events based on the maximum energy. These results as well as the peak amplitude are provided in Table III. Note that the bands of interest were also integrated and compared with the peak amplitudes, which were nearly identical. Inspection of Table III shows that the frequency of the peaks for the fundamental and overtones were similar between events 1 and 2 with the mean deviation between events being $2 \%$. The amplitudes had a mean deviation of $3 \%$, but consistently event 2 had the higher amplitude. As previously mentioned (and observed in Table III), the period between events 1 and 2 also had peaks at nearly the same frequencies, though with a decrease in amplitude ( $\sim 6 \mathrm{~dB}$ relative to event 1$)$. This gives strong evidence that the mechanisms leading to the two events were related.

Abdullah (1966) modeled a tornado as a compressible Rankine vortex, which predicts overtones when constrained to axisymmetric vibrations with a large vertical-to-radial wavelength ratio,

$$
f_{n}=\frac{(4 n+5) c}{4 d}
$$

Here, $n$ is a non-negative integer, and $d$ is the diameter of the vortex core. While Schecter (2012) identified several fundamental issues (discussed in more detail subsequently) with this analysis that precludes it as a potential mechanism, it is informative to compare the current observations that include overtones with these overtone predictions. Given the observed fundamental frequency from the current observation, the resulting overtones are compared with the predictions from Eq. (2) in Fig. 11. Given the fundamental issues, it is not surprising that there is a significant deviation between the current observations and that predicted by Abdullah (1966). The error bars on the current results are set based on the quality factor (i.e., 3$\mathrm{dB}$ reduction on each side of the peak). It is interesting that the

TABLE III. Frequency and amplitude of the fundamental $(n=0)$ and overtones $(n>0)$ from before, during, between events, and after both infrasound events.

\begin{tabular}{|c|c|c|c|c|c|}
\hline$N$ & 0 & 1 & 2 & 3 & 4 \\
\hline Frequency Band, a-b (Hz) & $5-14$ & $14-23$ & $23-32$ & $32-43$ & $43-52$ \\
\hline \multicolumn{6}{|c|}{ Before Tornado(es) $\left(-27<t_{r}<-7 \mathrm{~min}\right)$} \\
\hline$f_{n}(\mathrm{~Hz})$ & 13.8 & 15.2 & 25.1 & 41.7 & 50.2 \\
\hline Peak $(\mathrm{dB} / \mathrm{Hz})$ & 57.3 & 57.7 & 57.4 & 56.4 & 57.1 \\
\hline \multicolumn{6}{|c|}{ Infrasound Event $1\left(-4<t_{r}<11 \mathrm{~min}\right)$} \\
\hline$f_{n}(\mathrm{~Hz})$ & 8.3 & 18.2 & 27.6 & 38.1 & 45.8 \\
\hline Peak $(\mathrm{dB})$ & 73.1 & 66.2 & 63.5 & 61.3 & 58.7 \\
\hline \multicolumn{6}{|c|}{ Between Events $\left(11<t_{r}<19 \mathrm{~min}\right)$} \\
\hline$f_{n}(\mathrm{~Hz})$ & 8.3 & 19.1 & 27.6 & 38.1 & 47.9 \\
\hline Peak (dB) & 66.0 & 59.4 & 56.7 & 56.2 & 56.8 \\
\hline \multicolumn{6}{|c|}{ Infrasound Event $2\left(19<t_{r}<40 \mathrm{~min}\right)$} \\
\hline$f_{n}(\mathrm{~Hz})$ & 8.7 & 18.2 & 27.6 & 38.1 & 47.9 \\
\hline Peak (dB) & 76.0 & 69.7 & 65.1 & 62.0 & 59.2 \\
\hline \multicolumn{6}{|c|}{ After Tornado(es) $\left(52<t_{r}<72 \mathrm{~min}\right)$} \\
\hline$f_{n}(\mathrm{~Hz})$ & 5.3 & 19.6 & 25.0 & 39.1 & 51.2 \\
\hline Peak (dB) & 60.2 & 60.5 & 66.9 & 55.4 & 56.1 \\
\hline
\end{tabular}




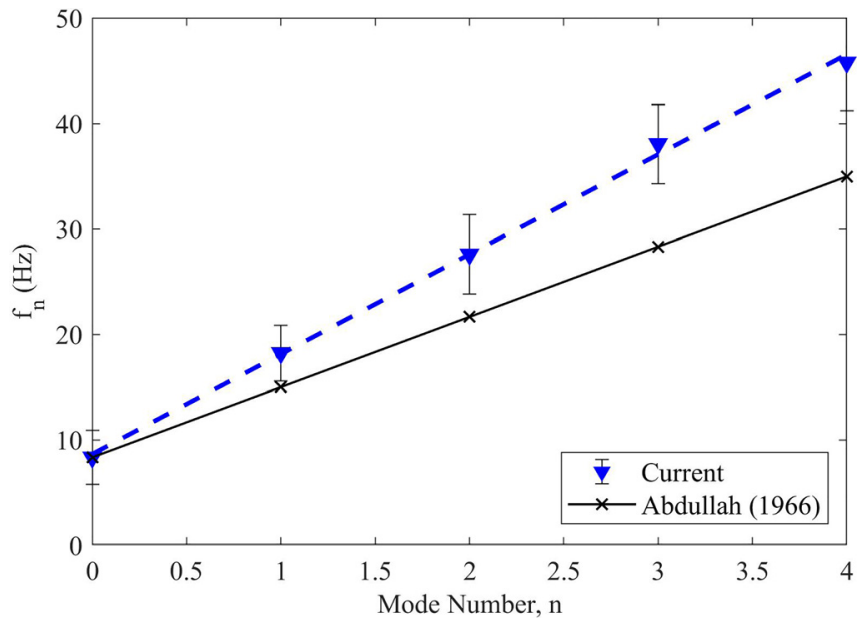

FIG. 11. (Color online) Fundamental and overtones during infrasound event 1 (tornado) compared with the predictions from Eq. (2) given the fundamental frequency.

observed overtones are linearly related $\left(f_{n}=9.47 n+8.64\right)$ but not pure harmonics (factor of $\sim 1.1$ rather than 1.0 between overtones). Linear regression analysis shows that both the linear slope $(9.47 \pm 0.56)$ and intercept $(8.64 \pm 1.38)$ were statistically significant $(p$-value $<0.05)$. Furthermore, using a $t$-test on the slope shows that the multiplication factor between overtones was between 1.07 and 1.21 with $95 \%$ confidence. This is a potentially important observation with respect to identifying a fluid mechanism for the infrasound production, but more tornado observations are required to explore these relationships in greater detail.

\section{B. Comparison with proposed mechanisms}

While the current work does not aim to attribute the observations to a specific mechanism, it can be informative to compare the current observations to proposed mechanisms. First, it should be noted that the higher frequency signature Frazier et al. (2014) observed and demonstrated to be consistent with aeroacoustic jet turbulence was not observed. This is expected since Frazier et al. (2014) measured larger tornadoes (EF-2, EF-4, EF-5) and noted that the frequency range was $10-100 \mathrm{~Hz}$, which means the current small tornado (EFU) would likely have a signature above $100 \mathrm{~Hz}$ (i.e., at a frequency higher than the current acoustic array could observe). Frazier et al. (2014) also notes that there was evidence of a lower frequency $(<2 \mathrm{~Hz})$ signature. The low frequency signal was assumed to be mostly due to wind noise, but there was sufficient coherence for successful beamforming to produce bearings to the tornado producing storms. This lower frequency signature has had several proposed mechanisms including radial oscillations (Abdullah, 1966; Bedard, 2005; Schecter, 2012), electromagnetic sources (Balachandran, 1983; Few, 1985; Pasko, 2009), co-rotating vortices (Powell, 1964; Georges, 1976), vortex-surface-interactions (Tatom et al., 1995), heat-related sources (Nicholls et al., 2004; Akhalkatsi and Gogoberidze, 2009; Schecter and Nicholls, 2010; Markowski and Richardson, 2010; Schecter, 2012), and non-equilibrium effects (Zuckerwar and Ash, 2006; Ash et al., 2011).
As previously mentioned, Schecter (2012) has demonstrated that the Abdullah (1966) analysis has fundamental issues: primarily (i) constraints on the tangential velocity fluctuations at $d / 2$ are nonphysical, (ii) requirements on outward propagation of acoustic waves are not met, and (iii) the solution includes modes for nonphysical acoustic sources outside of the vortex. In addition to the failure of Abdullah (1966) to predict the overtones of the current observations (Fig. 11), Fig. 12 compares the Abdullah (1966) predictions against available observations (Bedard 2005; Dunn et al., 2016; current). The diameter for the current observation was set at the maximum damage path width $(46 \mathrm{~m})$. The maximum damage path is not the vortex diameter, but is the best measure of the current observation since low-level radar data were not available. There is a low quality video of this tornado, in which the visible part of the funnel cloud has a maximum thickness that was $\sim 2.9$ times the width at the ground (Elbing et al., 2018a). This was used to provide a nominal uncertainty estimate for the current tornado diameter. Also, the error bars shown for the fundamental frequency was determined from the $95 \%$ confidence interval from the linear regression analysis of the spectral peaks evaluated at $n=0$. This shows that the current observation is the only measurement that falls on the predicted fundamental curve of Abdullah (1966), but with the tornado size uncertainty biased towards the higher harmonics. All of the other observations tend to align better with the first or second harmonic.

The prolonged signal that began prior to tornadogenesis is inconsistent with electromagnetic sources (impulsive sources) and vortex-surface-interactions (signals should not be observed prior to touching the ground). In addition, the frequencies of the current and previous observations were too high for those predicted based on co-rotating vortices, and the original postulate that motivated this mechanism has been disproven. Recent simulations (Schecter and Nicholls, 2010; Schecter, 2012) show that there is a lack of discernible infrasound in the absence of latent-heating effects and that non-tornadic thunderstorm cells produce infrasound from the melting level. This suggests that latent heat sources are a

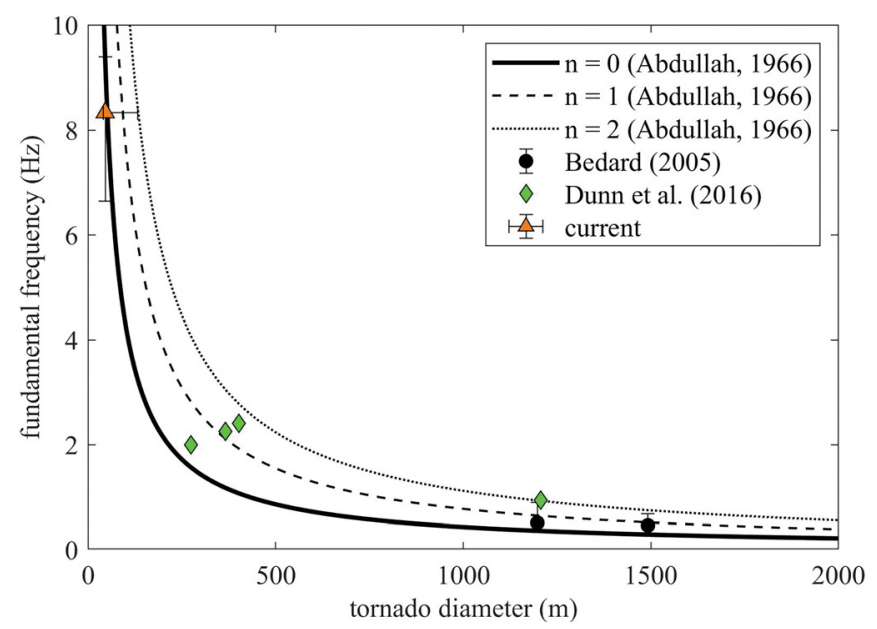

FIG. 12. (Color online) Available observations of infrasound fundamental frequencies associated with tornadoes with estimates of the tornado size compared against predictions from Abdullah (1966). 
likely mechanism, and simulations of the liquid-vapor transitions within a cloud were able to produce infrasound between 0.1 and $10 \mathrm{~Hz}$ (Akhalkatsi and Gogoberidze, 2009; Schecter and Nicholls, 2010). However, radial vortex oscillations including the non-columnar nature of a tornado (Schecter, 2012) and analysis incorporating non-equilibrium effects (Zuckerwar and Ash, 2006; Ash et al., 2011) are also consistent with observations. As noted by Frazier et al. (2014), there are likely multiple acoustic generation mechanisms active, which was based on their datasets exhibiting coherent acoustic energy within two distinct regimes $(<2 \mathrm{~Hz}$ and $10-100 \mathrm{~Hz}$ with larger tornadoes; EF-2, EF-4, and EF-5).

\section{Comparison with radar metrics}

Given a history of a complex relationship between hail production, vorticity, and infrasound production (Bowman and Bedard, 1971; Bedard, 2005; Schecter et al., 2008), the current infrasound observations (power spectral peak within the $5-14 \mathrm{~Hz}$ band, $\left.\Phi_{\max }\right)$ are compared with the radar metric NHAE in Fig. 13. In addition, the MRVD is included to demonstrate that infrasound production was not correlated with the large-scale rotation of the supercell that produced the tornado (i.e., the MRVD peak occurs before the rise in infrasound). Each parameter in Fig. 13 has been normalized to facilitate comparisons. The maximum values used to scale the pressure power spectra $\left(\Phi_{\max }\right), \mathrm{MRVD}$, and the NHAE were $0.3123 \mathrm{~Pa}^{2} / \mathrm{Hz}, 42.5 \mathrm{~m} / \mathrm{s}$, and 0.137 , respectively. The NHAE during event 1 generally follows the infrasound with their rise, peak, and roll off occurring at nearly the same time. This is consistent with observations by Schecter et al. (2008) that infrasound from a tornado-like vortex radiates infrasound in the $0.1-10 \mathrm{~Hz}$ range from the region where diabatic processes involving hail are active. It should be noted, however, that before the infrasound signal was observed, significant hail was produced from this storm as evident from both radar metrics and hail reports (Table I). Ultimately, these results suggest that infrasound from a tornadic storm

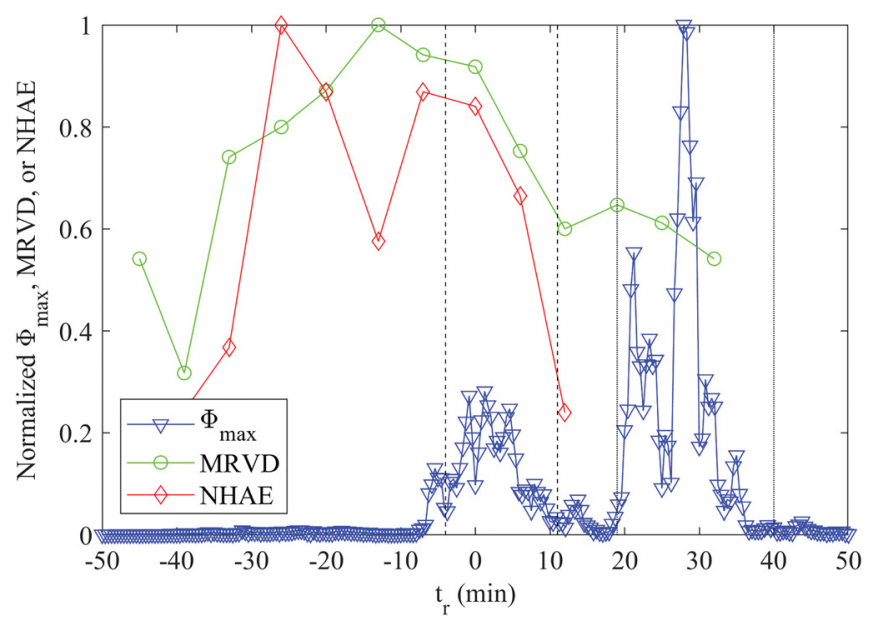

FIG. 13. (Color online) Time histories of the normalized pressure power spectra within the $5-14 \mathrm{~Hz}$ band $\left(\Phi_{\max }\right)$, MRVD, and the NHAE. Vertical dashed and solid lines denote the windows corresponding to infrasound event 1 and 2, respectively. could be connected with hail production, but hail production is not solely responsible for the infrasound production.

\section{SUMMARY AND CONCLUSIONS}

The current work presents infrasound measurements during a hail-producing supercell in Oklahoma on 11 May 2017, which produced an EFU tornado near Perkins, OK $(35.97,-97.04)$ at 2013 UTC with a path length of $0.16 \mathrm{~km}$ and damage path width of $46 \mathrm{~m}$. The storm was characterized using ground based measurements (Mesonet sites and a weather station at the infrasound sensors) of the air temperature, humidity, pressure, wind speed, and wind direction. The closest WSR-88D radar (KTLX) was too far $(\sim 70 \mathrm{~km})$ to measure maximum wind speed within the tornado, but the MRVD from low-level mesocyclone at $\sim 1 \mathrm{~km} \mathrm{ARL} \mathrm{and}$ NHAE were used to characterize the storm before, during, and after the tornado. There were reports of a possible second tornado after the first, but it was never confirmed due the storm being rain wrapped.

Two infrasound microphones with porous hoses as windscreens were recording $18.7 \mathrm{~km}$ from the tornado. The data below $\sim 5 \mathrm{~Hz}$ were contaminated with wind noise during the tornado, but the $5-50 \mathrm{~Hz}$ band produced data above the noise floor. During the tornado, a fundamental frequency of $8.3 \mathrm{~Hz}$ was observed with overtones at $18,29,36$, and $44 \mathrm{~Hz}$. While two microphones were insufficient to identify a definitive bearing angle, assumptions about the propagation and filtering the data between 5 and $50 \mathrm{~Hz}$ showed that the received infrasound was consistent with that expected from the storm core that produced the tornado. Furthermore, the bearing angle of the received signal during the confirmed tornado was within the uncertainty of the bearing angle measurement.

The spectral peaks observed during the tornado were present from -4 to $+40 \mathrm{~min}$ relative to the confirmed tornado (2013 UTC). The time trace shows two significant bursts, which the events were identified based on crosscorrelation between the microphones as event 1 ( -8 to $+10 \mathrm{~min})$ and event $2(20-30 \mathrm{~min})$. The power spectra from events 1 and 2 were nearly identical to the narrow period corresponding to the confirmed tornado. In addition, the period between events 1 and 2 showed similar structure in the power spectra, though at a lower amplitude. This suggests that the second event (as well as the period between) had similar active physical processes, and if a second tornado did occur, it was likely from the same geophysical process that produced the first tornado. The overtones observed in the spectra were shown to be linearly related, but not matching those predicted by Abdullah (1966). In addition, comparison of the current results (noting that the damage path width likely underestimates the vortex core size) and past observations (Bedard, 2005; Dunn et al., 2016) show Abduallah (1966) fails to predict the tornado size given the fundamental frequency. However, the separation of the available data does support the conjecture that a relationship between tornado size and the infrasound frequency does exist. While no specific mechanism was considered as a potential explanation for the current results, the consistency 
of the current observation (as well as those in the literature) with various proposed mechanisms were discussed. Electromagnetic sources, vortex-surface-interactions, and co-rotating vortices are inconsistent with observations, while latent heat effects, radial vortex oscillations that include non-columnar nature of a tornado, and non-equilibrium effects are consistent with observations. In addition, it was noted that the current observations did not measure at sufficiently high frequency $(>100 \mathrm{~Hz})$ to assess the aeroacoustic jet turbulence signature proposed in Frazier et al. (2014).

Finally, comparison of the infrasound with radar metrics produced insights about the infrasound and its relationship to the larger storm system. The MRVD of the base level of the mesocyclone was not well correlated with the infrasound, which suggests that the large-scale storm rotation is not a mechanism for the infrasound. This is consistent with other observations that the mesocyclone rotation is not responsible for the production of infrasound, but rather the tornado structure. The NHAE did appear to be correlated with the infrasound in the $5-14 \mathrm{~Hz}$ band during event 1 , which includes the confirmed tornado. Here the rise, peak, and roll off of both the infrasound and NHAE occurred nearly simultaneously. This supports the observation in the literature that the infrasound could be connected with the diabatic processes involving hail activity. However, the maximum observed NHAE for this storm occurred prior to the production of significant infrasound in the $5-14 \mathrm{~Hz}$ band, which is consistent with past observations that hail production alone (e.g., without rotation) does not produce infrasound. While it was unfortunate that the radar was too far from this tornado for characterization of the tornado, it does demonstrate the potential use of infrasound to characterize even weak tornadoes in remote locations where low-level radar coverage is poor. This work, combined with future observations of tornado infrasound, should provide insights into the fluid mechanism(s) responsible for infrasound production. In addition, there is a need for a more detailed analysis of hail production, vorticity, and infrasound production.

\section{ACKNOWLEDGMENTS}

The authors would like to thank Arnesha Threatt and Shannon Maher, who originally set up and deployed the infrasonic microphones. In addition, we would like to acknowledge the Oklahoma State University infrasound team (Jalen Golphin, Jared Hartzler, Shelby Webb, Alexis Vance, Katrine Hareland, Logan King, and Daniel Velasco) that have worked to maintain the array and inspect the data. This work was supported by the National Science Foundation (NSF) under Grant No. 1539070: CLOUD-MAP - Collaboration Leading Operational UAS Development for Meteorology and Atmospheric Physics (Timothy VanReken, Program Manager), National Oceanic and Atmospheric Administration (NOAA) under Grant No. NA18OAR4590307 as well as by B.R.E.'s Halliburton Faculty Fellowship endowed professorship.

Abdullah, A. J. (1966). "The musical sound emitted by a tornado," Mon. Weather Rev. 94, 213-220.

Akhalkatsi, M., and Gogoberidze, G. (2009). "Infrasound generation by tornadic supercell storms,” Q. J. Roy. Meteor. Soc. 135, 935-940.
Alberts, W. C. K. II, Tenney, S. M., and Noble, J. M. (2013). “Assessment of operational progress of NASA Langley developed windshield and microphone for infrasound," Army Research Laboratory Technical Report No. ARL-TR-6417.

Arnold, R. T., Bass, H. E., and Bolen, L. E. (1976). “Acoustic spectral analysis of three tornadoes,” J. Acoust. Soc. Am. 60, 584-593.

Ash, R. L., Zardadkhan, I., and Zuckerwar, A. J. (2011). "The influence of pressure relaxation on the structure of an axial vortex," Phys. Fluids 23, 073101.

Balachandran, N. K. (1983). "Acoustic and electric signals from lightning," J. Geophys. Res.-Oceans 88(C6), 3879-3884, https://doi.org/10.1029/ JC088iC06p03879.

Bedard, A. J. (1998). "Infrasonic and near infrasonic atmospheric sounding and imaging," in The Progress in Electromagnetics Research Symposium, 4th International Workshop on Radar Polarimetry, July 13-17, Nantes, France.

Bedard, A. J. (2005). "Low-frequency atmospheric acoustic energy associated with vortices produced by thunderstorms," Mon. Weather Rev. 133(1), 241-263.

Bedard, A. J., Bartram, B. W., Entwistle, B., Golden, J., Hodanish, S., Jones, R. M., Nishiyama, R. T., Keane, A. N., Mooney, L., Nicholls, M., Szoke, E. J., Thaler, E., and Welsh, D. C. (2004a). "Overview of the ISNET data set and conclusions and recommendations from a March 2004 workshop to review ISNET data," in Proceedings of the 22nd Conference on Severe Local Storms, October 4-8, Hyannis, MA.

Bedard, A. J., Bartram, B. W., Keane, A. N., Welsh, D. C., and Nishiyama, R. T. (2004b). "The infrasound network (ISNET): Background, design details, and display capabilities as an 88D adjunct tornado detection tool," in Proceedings of the 22nd Conference on Severe Local Storms, October 4-8, Hyannis, MA.

Bedard, A. J., and Georges, T. M. (2000). "Atmospheric infrasound," Phys. Today 53(3), 32-37.

Bendat, J. S., and Piersol, A. G. (2000). Random Data: Analysis and Measurement Procedures, 3rd ed. (John Wiley \& Sons, New York), 457-477.

Blom, P., Marcillo, O., and Arrowsmith, S. (2016). "Analysis and modeling of infrasound from a four-stage rocket launch," J. Acoust. Soc. Am. 139(6), 3134-3138.

Bowman, H. S., and Bedard, A. J. (1971). "Observations of infrasound and subsonic disturbances related to severe weather," Geophys. J. Int. 26, 215-242.

Brock, F. V., Crawford, K. C., Elliott, R. L., Cuperus, G. W., Stadler, S. J., Johnson, H. L., and Eilts, M. D. (1995). "The Oklahoma Mesonet: A technical overview," J. Atmos. Ocean. Tech. 12, 5-19.

Browning, K. A. (1965). "The evolution of tornadic storms," J. Atmos. Sci. 22, 664-668.

Cramer, O. (1993). "The variation of the specific heat ratio and the speed of sound in air with temperature, pressure, humidity, and $\mathrm{CO}_{2}$ concentration," J. Acoust. Soc. Am. 93(5), 2510-2516.

Dauchez, N., Hayot, M., and Denis, S. (2016). "Effectiveness of nonporous windscreens for infrasonic measurements," J. Acoust. Soc. Am. 139(6), 3177-3181.

Doviak, R. J., and Zrnić, D. S. (2006). Doppler Radar and Weather Observations, 2nd Ed. (Dover Publications, New York), pp. 562.

Dowling, D. R., and Sabra, K. G. (2015). "Acoustic remote sensing," Ann. Rev. Fluid Mech. 47, 221-243.

Dumas, E. J., Lee, T. R., Buban, M., and Baker, B. (2017). "Small unmanned aircraft system (sUAS) measurements during the 2017 Verification of the Origins of Rotation in Tornadoes Experiment Southeast (VORTEX-SE)," NOAA Technical Memorandum OAR-ARL-274, NOAA, Silver Spring, MD.

Dunn, R. W., Meredith, J. A., Lamb, A. B., and Kessler, E. G. (2016). "Detection of atmospheric infrasound with a ring laser interferometer," J. Appl. Phys. 120, 123109.

Elbing, B. R., and Gaeta, R. J. (2016). "Integration of infrasonic sensing with UAS (invited)," in The 8th Atmospheric and Space Environments Conference, AIAA Aviation, AIAA2016-3581, Washington, DC (June 1317) (doi:10.2514/6.2016-3581).

Elbing, B. R., Petrin, C. E., and Van Den Broeke, M. S. (2018a). "Infrasound measurements from a tornado in Oklahoma," Proc. Meet. Acoust. 33(1), 0450003.

Elbing, B. R., Petrin, C. E., and Van Den Broeke, M. S. (2018b). "Monitoring infrasound from a tornado in Oklahoma," J. Acoust. Soc. Am. 143, 1808. 
Few, A. A. (1985). "The production of lightning-associated infrasonic acoustic sources in thunderclouds," J. Geophys. Res. Atmos. 90(D4), 6175-6180, https://doi.org/10.1029/JD090iD04p06175.

Frazier, W. G., Talmadge, C., Park, J., Waxler, R., and Assink, J. (2014). "Acoustic detection, tracking, and characterization of three tornadoes," J. Acoust. Soc. Am. 135(4), 1742-1751.

Georges, T. M. (1973). "Infrasound from convective storms: Examining the evidence," Rev. Geophys. 11(3), 571-594, https://doi.org/10.1029/ RG011i003p00571.

Georges, T. M. (1976). "Infrasound from convective storms. Part II: A critique of source candidates," NOAA Technical Report ERL 380-WPL 49, NOAA, Silver Spring, MD.

Georges, T. M., and Greene, G. E. (1975). "Infrasound from convective storms. Part IV. Is it useful for storm warning?,” J. Appl. Meteorol. 14(7), 1303-1316.

Goerke, V. H., and Woodward, M. W. (1966). "Infrasonic observation of a severe weather system," Mon. Weather Rev. 94(6), 395-398.

Goudeau, B., Knupp, K. R., Frazier, W. G., Waxler, R., Talmadge, C., and Hetzer, C. (2018). "An analysis of tornado-emitted infrasound during the VORTEX-SE field campaign," in Proceedings of the 19th Symposium on Meteorological Observation and Instrumentation, January 6-11, Austin, TX.

Hart, D., and McDonald, T. (2009). "Infrasound sensor and porous-hose filter evaluation results," in Proceedings of the 2009 Monitoring Research Review: Ground-Based Nuclear Explosion Monitoring Technologies, September 21, Tucson, AZ, pp. 735-741.

Hemingway, B., Frazier, A. E., Elbing, B. R., and Jacob, J. D. (2017). "Vertical sampling scales for atmospheric boundary layer measurements from small unmanned aircraft systems (sUAS)," Atmosphere 8(9), 176.

Jacob, J. D., Chilson, P. B., Houston, A. L., and Smith, S. W. (2018). "Considerations for atmospheric measurements with small unmanned aircraft systems," Atmosphere 9(7), 252.

Johnson, J. B., and Ripepe, M. (2011). "Volcano infrasound: A review," J. Volcanol. Geoth. Res. 206, 61-69.

Jones, R. M., and Georges, T. M. (1976). "Infrasound from convective storms. III. Propagation to the ionosphere," J. Acoust. Soc. Am. 59(4), 765-779.

Le Pichon, A., Blanc, E., and Hauchecorne, A. (2010). Infrasound Monitoring for Atmospheric Studies, 1st ed. (Springer, New York).

Le Pichon, A., Herr, P., Mialle, P., Vergoz, J., Brachet, N., Garcés, M., Drob, D., and Ceranna, L. (2005). "Infrasound associated with 2004-2005 large Sumatra earthquakes and tsunami,” Geophys. Res. Lett. 32, L19802, https://doi.org/10.1029/2005GL023893.

Lee, T. R., Buban, M., Dumas, E., and Baker, C. B. (2019). "On the use of rotary-wing aircraft to sample near-surface thermodynamic fields: Results from recent field campaigns," Sensors 19(1), 10.

Lyza, A. W., and Knupp, K. R. (2018). "A background investigation of tornado activity across the Southern Cumberland Plateau terrain system of northeastern Alabama," Mon. Weather Rev. 146(12), 4261-4278.

Markowski, P., and Richardson, Y. (2010). Mesoscale Meteorology in Midlatitudes (John Wiley \& Sons, New York).

McDonald, J. A. (1974). "Naturally occurring atmospheric acoustical signals," J. Acoust. Soc. Am. 56(2), 338-351.

McPherson, R. A., Fiebrich, C., Crawford, K. C., Elliott, R. L., Kilby, J. R., Grimsley, D. L., Martinez, J. E., Basara, J. B., Illston, B. G., Morris, D. A., Kloesel, K. A., Stadler, S. J., Melvin, A. D., Sutherland, A. J., and Shrivastava, H. (2007). "Statewide monitoring of the mesoscale environment: A technical update on the Oklahoma Mesonet," J. Atmos. Ocean. Technol. 24, 301-321.

Mutschlecner, J. P., and Whitaker, R. W. (2005). "Infrasound from earthquakes," J. Geophys. Res. 110, D01108, https://doi.org/10.1029/ 2004JD005067.

Nicholls, M. E., Pielke, R. A., and Bedard, A. J. (2004). "Preliminary numerical simulations of infrasound generation processes by severe weather using a fully compressible numerical model," in Proceedings of the 22nd Conference on Severe Local Storms, October 4-8, Hyannis, MA.

NOAA (2017). "NOAA NCEI Storm Event Database," Oklahoma/Payne Co./May 11, 2017/Tornado, NOAA, Silver Spring, MD.

Noble, J. M., and Tenney, S. M. (2003). "Detection of naturally occurring events from small aperture infrasound arrays," in Proceedings of the Battlespace Atmospheric and Cloud Impacts on Military Operations Conference, September 9-11, Monterey, CA.

Ostashev, V. E., Chunchuzov, I. P., and Wilson, D. K. (2005). "Sound propagation through and scattering by internal gravity waves in a stably stratified atmosphere," J. Acoust. Soc. Am. 118(6), 3420-3429.
Pasko, V. P. (2009). "Mechanism of lightning-associated infrasonic pulses from thunderclouds," J. Geophys. Res. Atmos. 114(D8), D08205, https:// doi.org/10.1029/2008JD011145.

Pepyne, D. L., and Klaiber, S. (2012). "Highlights from the 2011 CASA infrasound field experiment," in Proceedings of the 92nd American Meteorological Society Annual Meeting, January 22-26, New Orleans, LA.

Pitre, K. M., and Petculescu, A. (2019). "Porous domes as wind noise filters for infrasound sensing on Mars," Planet. Space Sci. 167, 33-41.

Powell, A. (1964). "Theory of vortex sound," J. Acoust. Soc. Am. 36, 177-195.

Prassner, J. E., and Noble, J. M. (2004). "Acoustic energy measured from mesocyclone and tornadoes in June 2003," in Proceedings of the 22nd Conference on Severe Local Storms, October 4-8, Hyannis, MA.

Rinehart, H. S. (2012). "Application of a blind source separation algorithm for the detection and tracking of tornado-generated infrasound emissions during the severe weather outbreak of 27 April 2011," J. Acoust. Soc. Am. 132, 2074

Rinehart, H. S. (2018). "Direct detection of tornadoes using infrasound remote sensing: Assessment of capabilities through comparison with dual polarization radar and other direct detection measurements," General Atomics Final Progress Report, NOAA Grant No. NA160AR4590205, NOAA, Silver Springs, MD.

Sabatini, R., Marsden, O., Bailly, C., and Gainville, O. (2019). "Threedimensional direct numerical simulation of infrasound propagation in the Earth's atmosphere," J. Fluid Mech. 859(25), 754-789.

Schecter, D. A. (2012). "A brief critique of a theory used to interpret the infrasound of tornadic thunderstorms," Mon. Weather Rev. 140(7), 2080-2089.

Schecter, D. A., and Nicholls, M. E. (2010). "Generation of infrasound by evaporating hydrometeors in a cloud model," J. Appl. Meteorol. Clim. 49, 664-675.

Schecter, D. A., Nicholls, M. E., Persing, J., Bedard, A. J., Jr., and Pielke, R. A., Sr. (2008). "Infrasound emitted by tornado-like vortices: Basic theory and a numerical comparison to the acoustic radiation of a single-cell thunderstorm," J. Atmos. Sci. 65, 685-713.

Shams, Q. A., Zuckerwar, A. J., Burkett, C. G., Weistroffer, G. R., and Hugo, D. R. (2013). "Experimental investigation into infrasonic emissions from atmospheric turbulence," J. Acoust. Soc. Am. 133(3), 1269-1280.

Shams, Q. A., Zuckerwar, A. J., and Sealey, B. S. (2005). "Compact nonporous windscreen for infrasonic measurements," J. Acoust. Soc. Am. 118(3), 1335-1340.

Shang, C., Teng, P., Lyu, J., Yang, J., and Sun, H. (2019). "Infrasonic source altitude localization based on infrasound ray tracing propagation model," J. Acoust. Soc. Am. 145(6), 3805-3816.

Smith, S. W., Chilson, P. B., Houston, A. L., and Jacob, J. D. (2017). "Catalyzing collaboration for multi-disciplinary UAS development with a flight campaign focused on meteorology and atmospheric physics," in Proceedings of AIAA Information Systems-AIAAInfotech@Aerospace, January 9-13, Grapevine, TX, AIAA-2017-1156.

Talmadge, C. L. (2018). "Wind noise reduction at infrasound frequencies using large domes," J. Acoust. Soc. Am. 143(3), 1808.

Talmadge, C., and Waxler, R. (2016). "Infrasound from tornados: Theory, measurement, and prospects for their use in early warning systems," Acoust. Today 12(1), 43-51.

Tatom, F. B., Knupp, K. R., and Vitton, S. J. (1995). "Tornado detection based on seismic signal," J. Appl. Meteorol. 34, 572-582.

Threatt, A. (2016). "Investigation of natural and anthropomorphic sources of atmospheric infrasound," M.S. thesis, Oklahoma State University, Stillwater, OK.

Van Den Broeke, M. S. (2017). "Polarimetric radar metrics related to tornado life cycles and intensity in supercell storms," Mon. Weather Rev. 145, 3671-3686.

Van Den Broeke, M. S., Straka, J. M., and Rasmussen, E. N. (2008). "Polarimetric radar observations at low levels during tornado life cycles in a small sample of classic Southern Plains supercells," J. Appl. Meteorol. Clim. 47, 1232-1247.

Wagner, T. J., Klein, P. M., and Turner, D. D. (2019). "A new generation of ground-based mobile platforms for active and passive profiling of the boundary layer,” Bull. Am. Meteorol. Soc. 100(1), 137-153.

Waxler, R. M., and Assink, J. D. (2017). "NCPAprop-A software package for infrasound propagation modeling," J. Acoust. Soc. Am. 141, 3627.

Waxler, R., Evers, L. G., Assink, J., and Blom, P. (2015). "The stratospheric arrival pair in infrasound propagation," J. Acoust. Soc. Am. 137(4), 1846-1856. 
Waxler, R., and Gilbert, K. E. (2006). "The radiation of atmospheric microbaroms by ocean waves," J. Acoust. Soc. Am. 119(5), 2651-2664.

Young, J. M., and Greene, G. E. (1982). “Anomalous infrasound generated by the Alaskan earthquake of 28 March 1964," J. Acoust. Soc. Am. 71(2), 334-339.
Zuckerwar, A. J., and Ash, R. L. (2006). "Variational approach to the volume viscosity of fluids," Phys. Fluids 18, 047101.

Zuckerwar, A. J. (2010). "Theory of compact nonporous windscreens for infrasonic measurements," J. Acoust. Soc. Am. 127(6), $3327-3334$ 